J. Perinat. Med. 16 (1988) 349

\title{
On a portable memory device for physical activities and informations of maternal perception
}

\author{
Toshitsune Hasegawa $^{1}$, Hiroyuki Horio ${ }^{2}$, Masaaki Makikawa ${ }^{2}$, Hitomi Bunki ${ }^{3}$, Ki- \\ kuko Sasaki $^{4}$, Masaji Utsu ${ }^{4}$, Sigeki Sakakibara ${ }^{4}$, Tooru Kanzaki ${ }^{4}$, Hideki Kobayashi ${ }^{4}$, \\ and Yoshihide $\mathrm{Chiba}^{4}$ \\ 1 College of Biomedical Technology, Osaka University, Toyonaka, and \\ 2 National Cardiovascular Center Research Institute, Suita, Osaka, Japan \\ ${ }^{3}$ Department of Orthopaedic Surgery, Shiga University of Medical Science, Otsu, \\ Japan \\ ${ }^{4}$ Department of Perinatology, National Cardiovascular Center, Suita, Osaka, \\ Japan
}

\section{Introduction}

Recently, the development of micro electronics is so remarkable that it is easy to develop a microcomputer based portable instrument, which enables us to gather the clinical information from a patient in daily life. In management of chronic diseases like high risk pregnancy, it is important for attending doctors to know the change in disease condition in daily life, either at home or in hospital. Under present conditions, clinical informations about patient's disease condition can be obtained only periodically when she comes to the hospital, and the changes about her disease condition in daily life must be acquired only through patient's uncertain impressions. From this point of view, we have developed a portable computerized memory device to record the physical activities with maternal perception of fetal movement and uterine contraction in daily life, both at home and at work.

\section{Instrument and Methods}

A small size, light weight, and battery-driven device is desirable for measuring physical activities during home daily life. As the time and a frequency of fetal movement, lower abdominal pain, and uterine contraction are clinically important, we have developed the portable memory device using battery-driven CMOS microcomputer with a real

\section{Curriculum vitae}

TOSHITSUNE HASEgawa was born in 1936. He studied electronics in the department of electronics, Faculty of Engineering and received $M S$ from Osaka University in 1964. From 1964-1977 he worked at Toa Electric Co. From 1977-1984 he returned to the Department of Obstetrics \& Gynecology, School of Medicine, Osaka University. From 1984-1986 he worked at National Cardiovascular Center Research Institute. At present he is teaching and working at College of Biomedical Technology, Osaka University. His main fields of interest are medical engineering, medical information systems, and obstetrics.

time clock. This device was named "MICRO" from acronyms of Medical Information Collection RObot.

\subsection{Hardware}

"MICRO" system consists of two parts, one is a portable memory device called a CPU unit, for an ambulatory patient and another is a interface unit (figure 1). It is an advantage in size, weight and 
CPU unit

INTERFACE unit

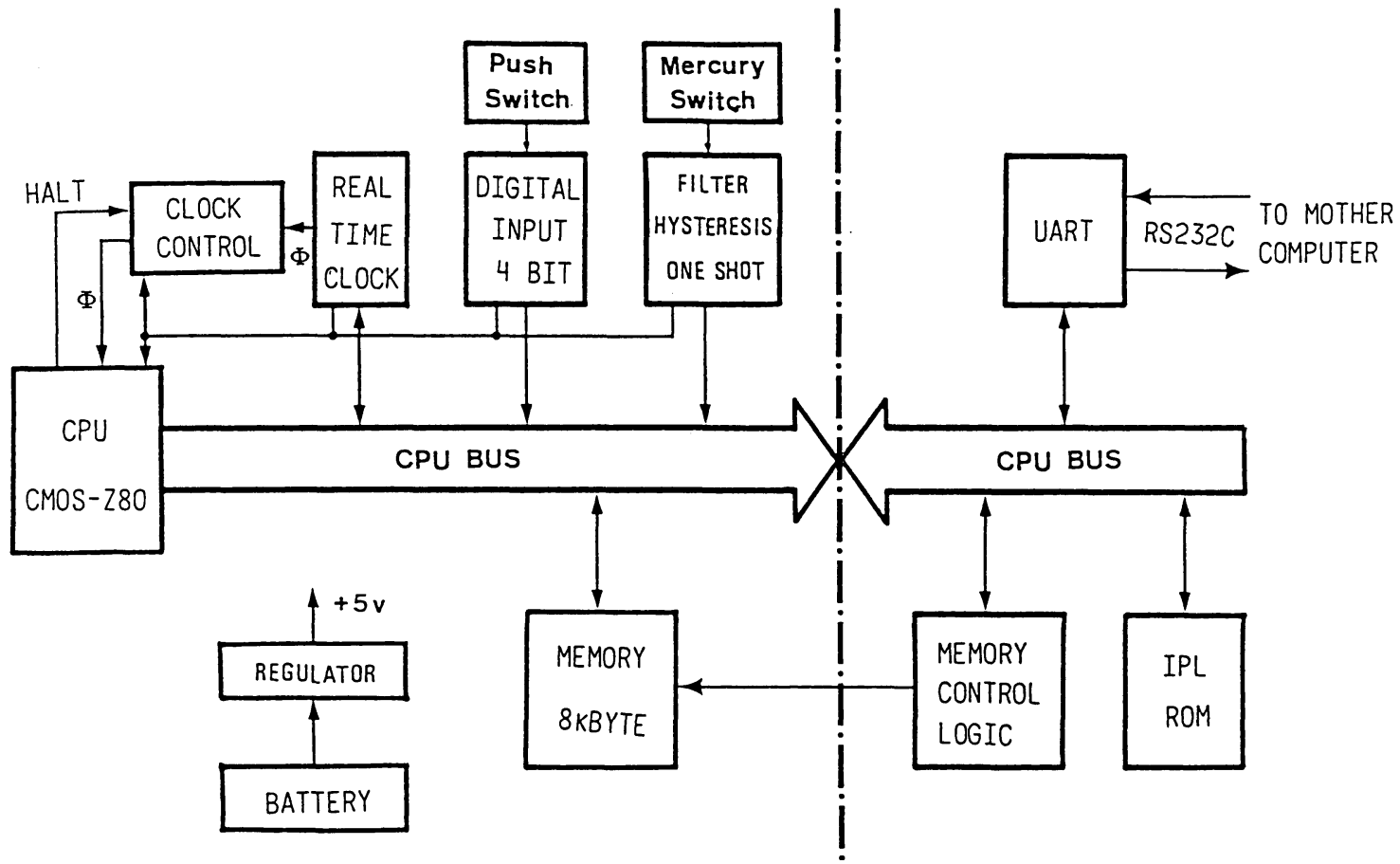

Figure 1. The hardware block diagram of a portable memory device called "MICRO". This system consists of two parts. One is the CPU unit carried out by a patient and other is the inferface unit to communicate with mother computer.

MOTHER COMPUTER

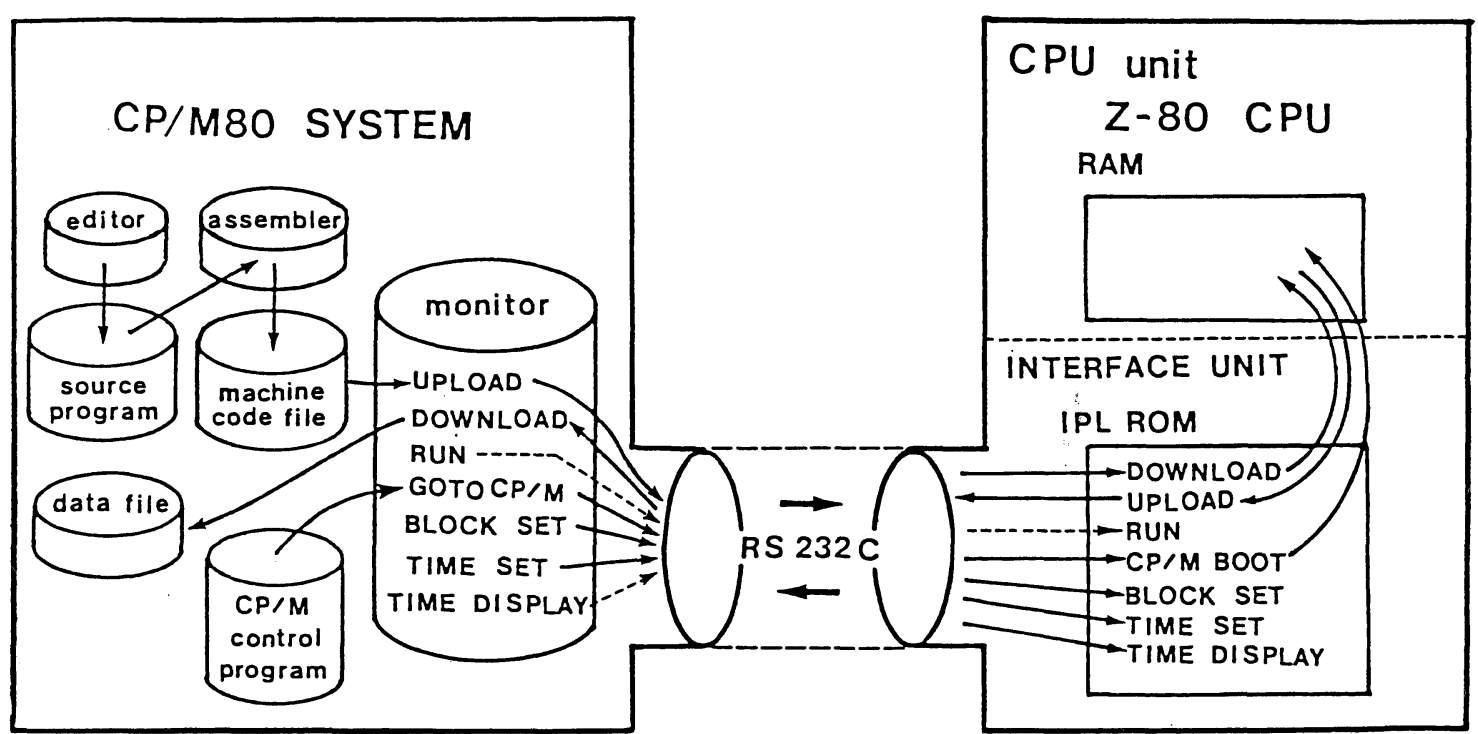

Figure 2. Software development tools between "MICRO" and mother computer. The "MICRO" system communicates with mother computer via RS232C line. 
power dissipation to divide this system in two parts (the CPU unit and the interface unit), because no communication device is needed when engaged in measurement.

The CPU unit using a battery-driven CMOS Z80 8 bit computer is so small that a patient can carry about. The size is $10.7 \times 8 \times 3 \mathrm{~cm}$ and its weight is $240 \mathrm{~g}$ including battery. The battery is 9 volt 006P type and the regulator IC is prepared for 5 volt supply. The CPU unit has a real time clock for memorizing events by pushbutton switches. The data from the mercury switch is counted and memorized automatically according to physical activities. A 8 kbyte RAM (Random-AccessMemory) device is equipped for the program and data storage. The role of the interface unit is to transmit a program and a recorded data between the mother computer and the CPU unit via RS232C serial line. A UART (Universal Asynchronous Receiver Transmitter) device is equipped in this unit. For these data exchanges, the interface unit has the control program in the IPL ROM (Read-Only-Memory).

\subsection{Software}

We think that the software support is much important for these instruments using a microcomputer, particularly in the software debug. The poor selection of the CPU can not support software tools such as assembler, linker, high level language

- Program loading to MICRO via RS232C

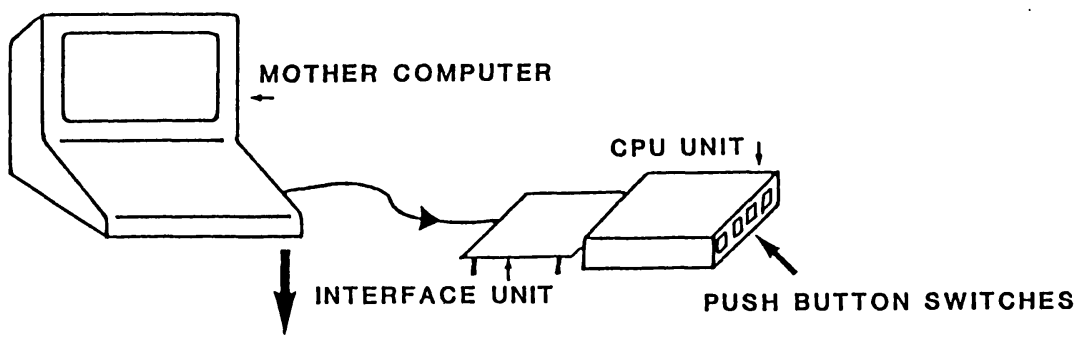

- Data recording

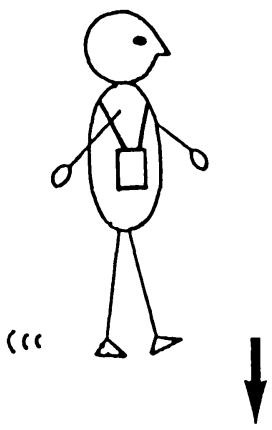
PUSH BUTTON SWITCHES
Maternal perception of
1. lower abdominal pain
2. uterine contraction
3. fetal movement

\section{MERCURY SWITCH}

physical activity counter

$\max 240$ counts $/ 4$ minutes

- Data retrieval and analysis

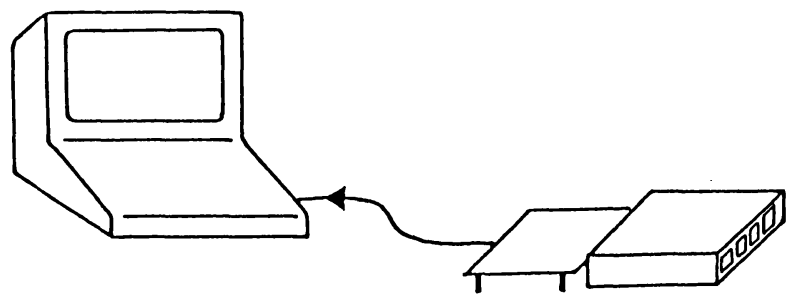

Figure 3. The sequence of program loading, data gathering and processing. 
and debugger. We select the Z80 CPU, because the operating system, called $\mathrm{CP} / \mathrm{M} 80$ is widely used in a 8 bit microcomputer (figure 2). The world wide software support can be taken on this "MICRO" system.

Widely used method in these instruments is that the program is fixed in the ROM and the data is stored in the RAM. In this method, the recording program cannot easily be changed according to the purpose of the measurement, and the period for developing and debugging the program needs too much. On the contrary, the CPU unit taken out by patient has only RAM. This method has profit in its size, weight and power dissipation. Because the communication devices such as the UART and the communication program inside the ROM need not be used on monitoring the patient. On occasional calls to communicate with the mother computer, the CPU unit is attached to the interface unit and the program and the data is transmitted via RS232C line using the ROM program mounted on the interface unit. This RS232C serial line can be easily expanded by the telephone line using the modem. This means that the communication of program and data between the patient's home and the hospital can be easily taken by the telephone line.

\subsection{Measurement of physical activities and others}

The sequence of program loading, data gathering and processing is as follows (figure 3). Initially, the CPU unit is attached to the interface unit. The date and time is set to the clock by the mother computer via $\mathrm{RS} 232 \mathrm{C}$ line and the recording program is also downloaded to the "MICRO" system. After detaching the CPU unit, the recording program is started. It is taken out by the patient and she returns to home with this device hanging at her side. The CPU unit is equipped with pushbotton switches on the upper side and the mercury switch inside. Three push botton switches are used for the maternal perception of lower abdominal pain, uterine contraction and fetal movement. The event time of these perceptions are recorded by pressing the corresponding switch. The mercury switch is served as a shock sensor, which will be set on when it is inclined above about 10 degrees or received a shock. Its waveform is shaped by filter, hysteresis and one-shot circuit. The physical activites of patient are measured by counting ON and OFF actions of the mercury switch caused by her motion and are recorded automatically by wearing this unit all day long. The continuously recordable time of this device is more than two weeks. The physical activities are measured by counting ON-OFF actions of the mercury switch in each 4 minute time slot and the program stores 1 byte data on every 4 minutes.

There is a photograph of a pregnant woman who has this device inside her pouch (figure 4). She is expected to push the corresponding switch when she is conscious of fetal movement, uterine contraction and lower abdominal pain. This device has a buzzer for a feedback. There are some applications using a buzzer feedback system. For example, when sampled physical activities exceed the prepared point, it is easy to sound the buzzer warning to the patient. This method will prevent a pregnant woman from an instantaneous overwork. After withdrawal from the patient, the CPU unit is attached again to the interface unit and sends the recorded data to the mother computer. The recorded data is analyzed and the result is displayed and printed out.

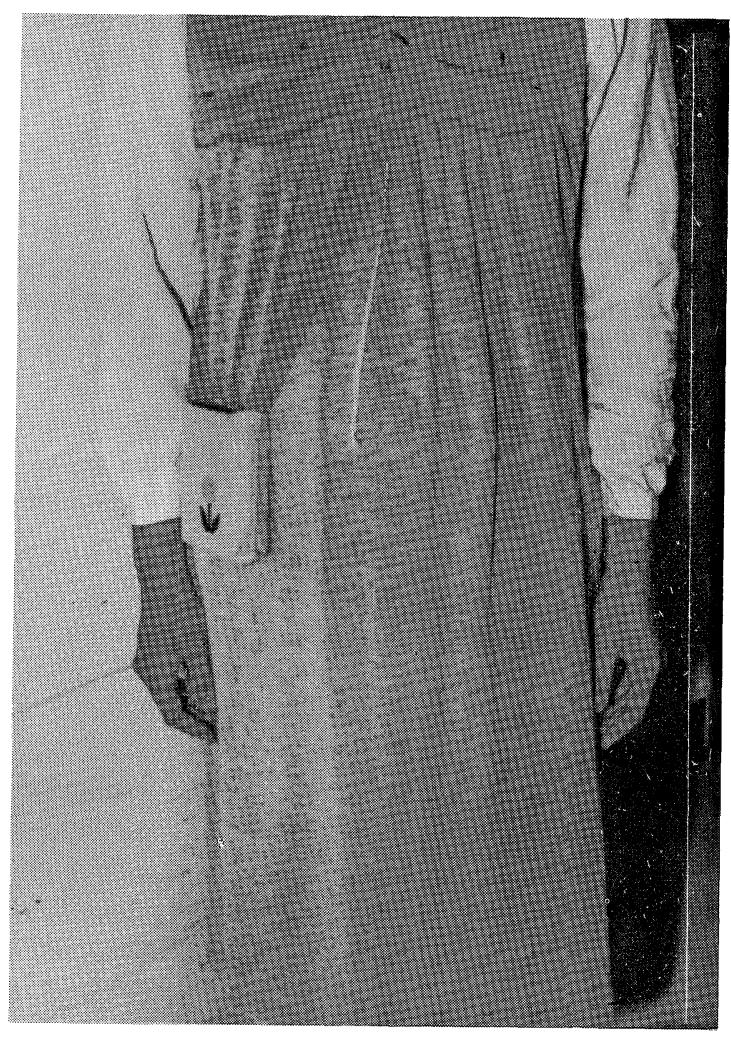

Figure 4. A pregnant woman who has this device inside her pouch. 


\section{Results}

One day recording of a 40-week pregnant patient in hospital and a 29-week pregnant patient in normal life is shown (figure 5). On the data during hospitalization, the upper graph indicates the physical activites. The vertical axis is the physical activities counted by mercury switch at every 4 minutes intervals and the horizontal axis is 24 hours. This graph indicates one day activity pattern of the patient. The lower graph shows mater-

\section{During hospltalization}

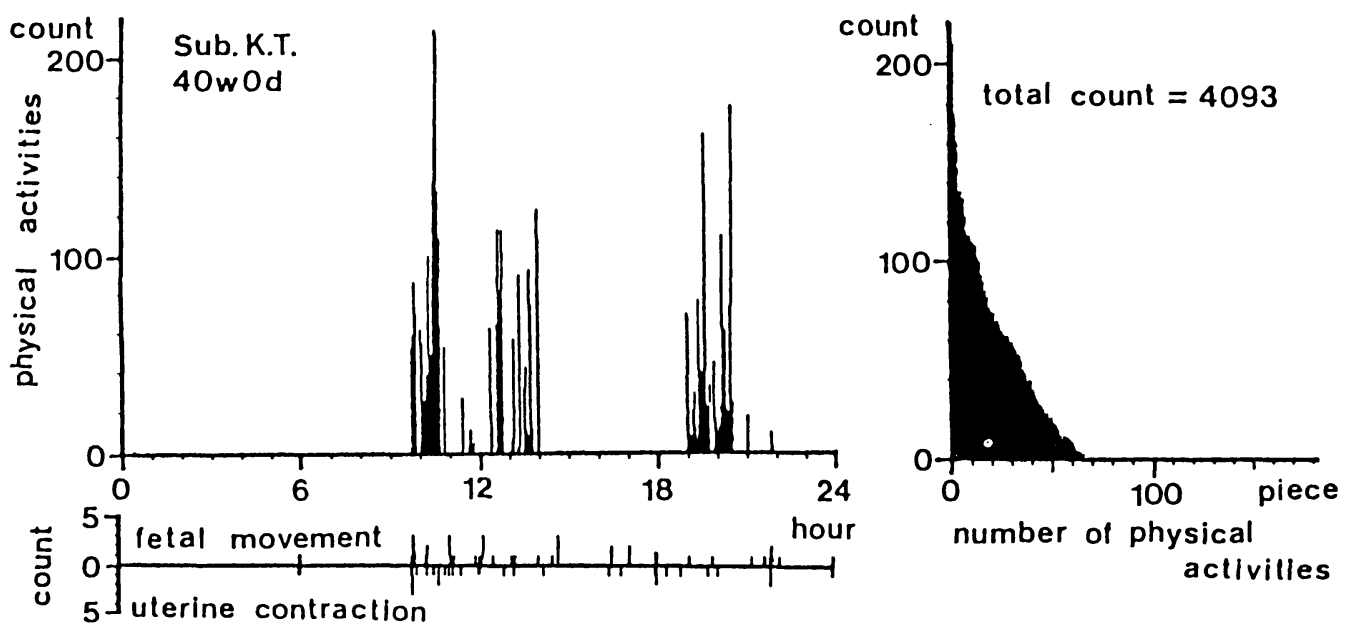

\section{In normal IIfe}
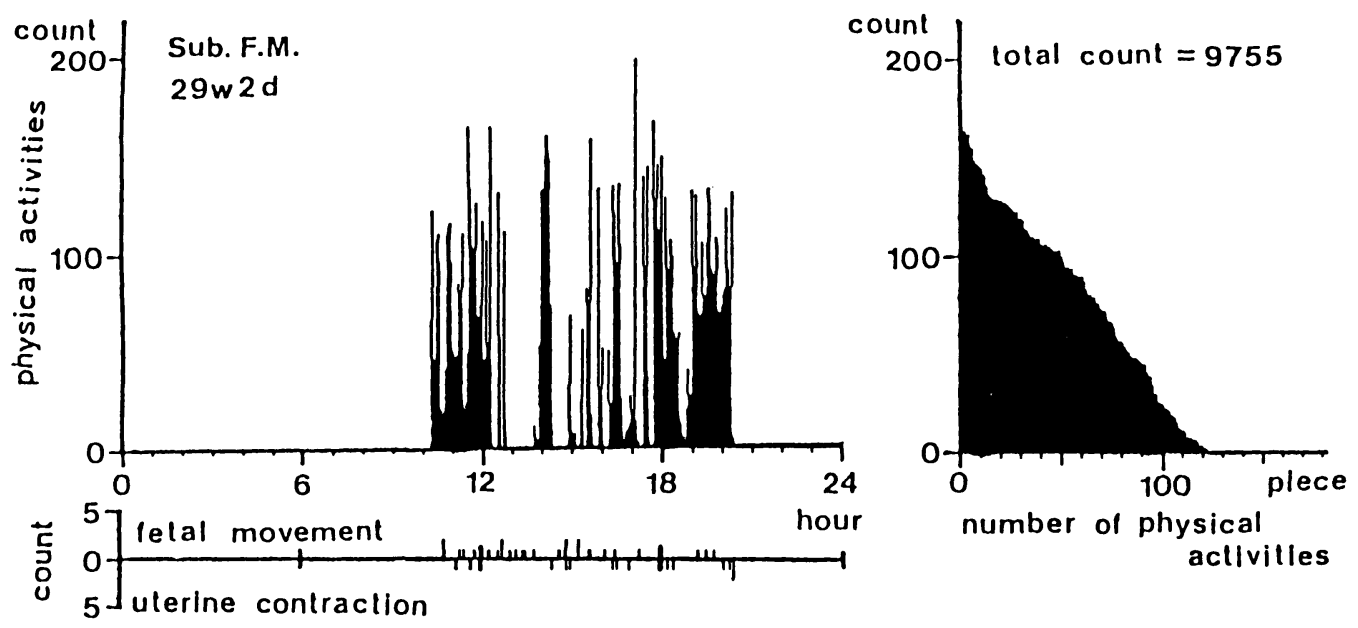

$$
\begin{aligned}
& \text { Physical activitles and maternal perception } \\
& \text { of fetal movement and uterine contraction }
\end{aligned}
$$

$$
\begin{aligned}
& \text { Numerical order of } \\
& \text { physical aclivilies }
\end{aligned}
$$

Figure 5. One day recording of physical activities and maternal perception of fetal movement and uterine contraction. The difference between normal life and hospitalization is clearly shown on physical activities. 
nal perception of fetal movement and uterine contraction on the same day. The right side graph shows numerical order of physical activities. The shape of this graph indicates the total activity pattern per day and this area is total load for the patient. The data in normal life indicates much physical load to the patient. These data show the quantitative difference in physical activites between rest in bed and normal daily life.

We have observed five pregnant patients for one week and have detected the variation of physical activities at home (figure 6). The doctor prescribed a rest for her at home because of a threatened preterm delivery. There was a difference in physical activities on each day from this recording. On the lower graph indicating the time of maternal
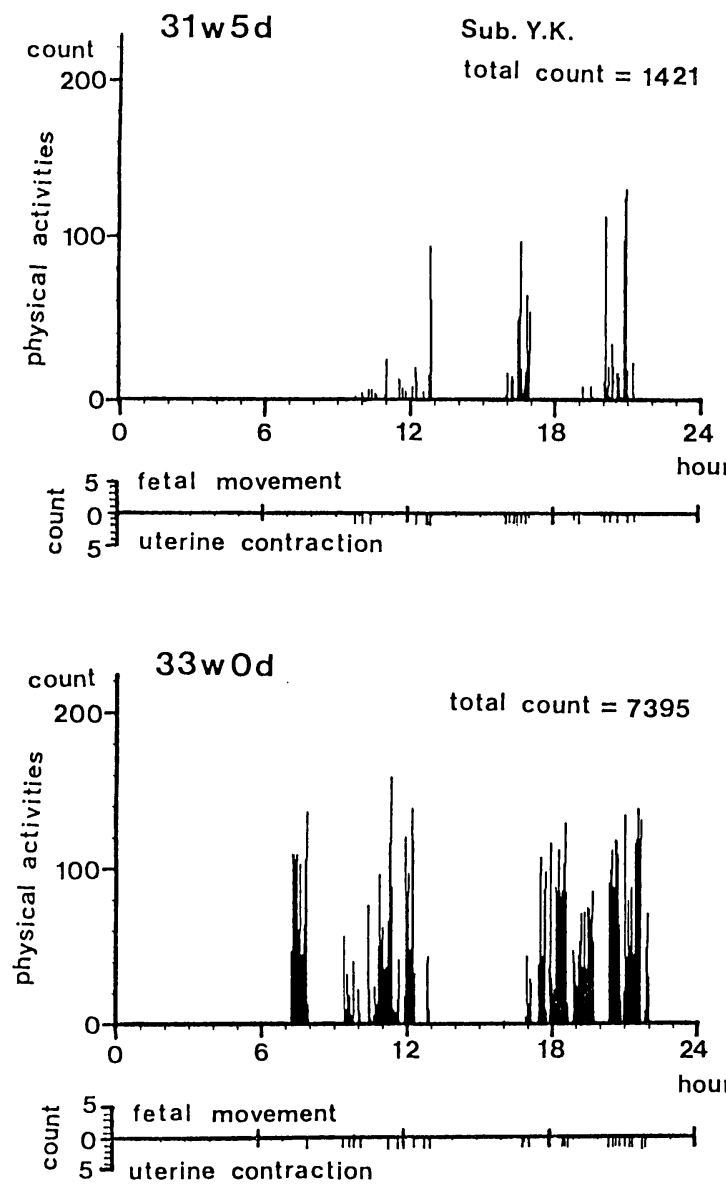

Figure 6. Variation of physical activities at one patient during home life. There are many different patterns in total load and peak value on each day. perception, her uterine contraction has occurred at times and it has depended on the physical activities. Consequently, there is a problem in prescribing a rest to a patient. However, we can avoid these physical overload of the patient by this device.

\section{Discussion}

We have evaluated the sensitivity of physical activities between the mercury switch sensor and others. They were the heart rate and the oxygen consumption. The heart rate was recorded by telemetric ECG signal and the oxygen consumption was measured by the OXYLOG (Morgan Corporation, England). The physical load assigned to a subject had four variations. They were normal walk mode, standing work mode, desk work mode, and rest mode on chair. The standing work was filing documents to a cabinet. The desk work was the packing on the desk. There were six healthy adults consisting of three men and three women. The relative sensitivity among three parameters were compared (figure 7). The numerical count from the mercury switch was normalized at $100 \%$ on walk mode and other parameters had

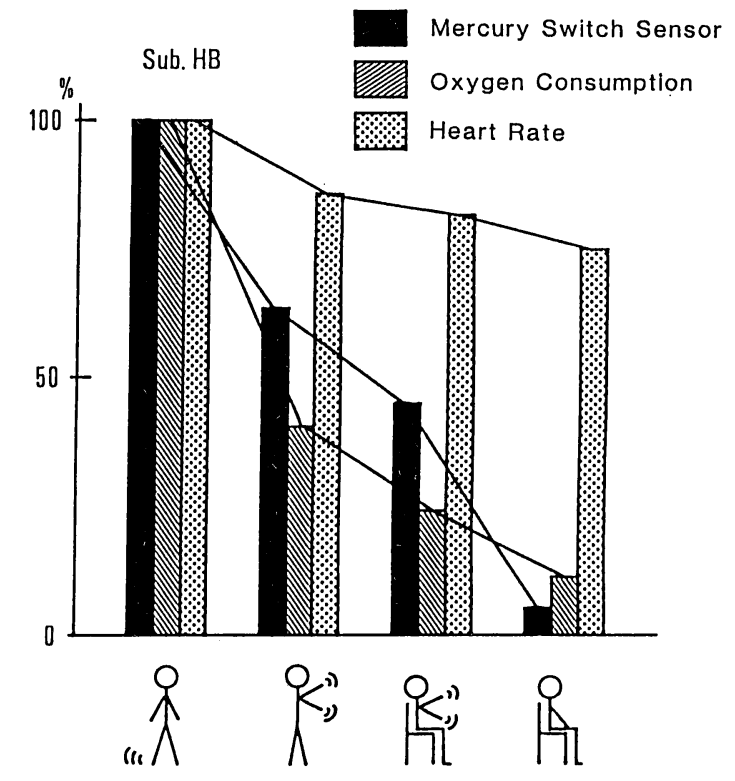

Figure 7. Sensitivity of physical activities between mercury switch sensor and heart rate and oxygen consumption. The physical loads to a subject were normal walk, standing work, desk work, and rest on chair. 
the same treatment. In this figure, the black bar graph was the result from the mercury switch sensor, and the stripe bar was from the oxygen consumption monitor, and the dotted bar was from the heart rate. The actual data in walk mode is 102 beat per minute on heart rate and 0.36 liter per minute on oxygen consumption $\left(\mathrm{V}_{2}\right)$, and in desk work mode, $85 \mathrm{bpm}$ and 0.09 liter per minute, respectively. Other data from another subjects had the same pattern.

The heart rate had not so much changes according to the physical load as others, and the mercury switch sensor was well related to the oxygen consumption rate. From these results, the mercury switch sensor can be used enough to measure physical activities in these mild exercise. This sensor is more convenient than the oxygen consumption monitor or the heart rate monitor, because a patient has only to wear this unit. These results indicate that the physical activites of the patient can be easily monitored by the "MICRO" CPU unit.

The problem about physical stress and fatigue is not clearly in the risk factors associated with low birth weight [1]. The rest and exercise of pregnant woman have been much discussed, but large number of variables has been influenced to the fetal outcome [2]. Using this device, we can measure not only the quantitative parameters about rest and mild exercise but also the relation between physical activities and fetal movement and uterine contraction in daily life.

Another application about her condition is to measure the response of the drug dosages and we are now engaged in this application. In the near future, we will develop the "MICRO" to have intelligence, to gather data according to patient condition and to take care of the patient.

\section{Summary}

The condition of patients must be known to attending doctors for adequate management of a disease, particularly of high risk pregnancy. For this purpose, we have developed a portable computerized disease condition memory device to record the physical activities with maternal perception of fetal movement and uterine condition in daily life, both at home and during work. This device taken out by the patient is a small battery-driven CMOS 8 bit computer system (size: $107 \times 80 \times 30 \mathrm{~mm}$, $240 \mathrm{~g}$ ) and is equipped with push-botton switches on the upper side and a mercury switch inside it. The time of maternal perception of fetal movement and uterine contraction are recorded by the patient pressing the corresponding switch. Meanwhile the mercury switch serves as a acceleration sensor and the physical activites were

measured by counting ON-OFF actions of the mercury switch caused by her movements. Consequently, the device has recorded physical activities automatically by wearing this unit all day long. The continuously recordable time is more than two weeks. The evaluation about the sensitivity of physical activity measurement has indicated that the mercury switch sensor was well related to the oxygen consumption rate in rest and mild exercise. Using this device to five pregnant women, the data showed the quantitative diffërence in physical activites between rest in bed and normal home life, and daily changes could be clearly observed. From these results, the physical activities and the condition of the patient in daily life can be followed by this device.

Keywords: Ambulatory monitoring, fetal monitoring, physical activity monitoring.

\section{Zusammenfassung}

Über ein tragbares Speichergerät für physische Vorgänge und Informationen über mütterliche Wahrnehmung

Der Zustand der Patienten, vor allem bei Hochrisikoschwangeren, muß den behandelnden Ärzten bekannt sein, damit eine angemessene Behandlung der Krankheit gewährleistet ist. $\mathrm{Zu}$ diesem Zweck haben wir einen computerisierten Krankheitszustands-Speicher entwikkelt, der physische Vorgänge mütterlicher Wahrnehmung von fetalen Bewegungen und des uterinen Zustands im täglichen Leben, d.h. zu Hause und auf der Arbeitsstelle, aufzeichnet. Dieses von der Patientin getragene Gerät besteht aus einem kleinen batteriebetriebenen CMOS
8 bit-Computer $(107 \times 80 \times 30 \mathrm{~mm}, 240 \mathrm{~g})$ und ist außen mit Drucktasten und innen mit einem Quecksilberschalter ausgestattet. Zeitpunkte der Wahrnehmung fetaler Bewegungen und Uteruskontraktionen werden aufgezeichnet, indem die Patientin die entsprechende Taste betätigt. Der Quecksilberschalter wirkt als Beschleunigungsaufnehmer, und die physischen Aktivitäten werden durch Zählen der durch die Bewegungen verursachten EIN-AUS-Schaltungen des Quecksilberschalters registriert.

Auf diese Weise registriert dieses Gerät automatisch über den ganzen Tag die physischen Vorgänge. Über mehr als 
2 Wochen können kontinuierlich Daten aufgezeichnet werden.

Die Auswertung der Sensitivität der physischen Aktivitätsmessung ergab, daß der Aufnehmer in Form eines Quecksilberschalters in einer engen Beziehung zum Sauerstoffverbrauch in Ruhe und bei geringer Aktivität stand. Die Daten von 5 schwangeren Frauen zeigten quantitative Unterschiede in den physischen Vorgängen bei Bettruhe und bei normalem häuslichen Leben und ließen deutliche tägliche Schwankungen erkennen. Diese Ergebnisse demonstrieren, daß die physischen Vorgänge und der Zustand der Patientinnen im Alltag mit Hilfe dieses Gerätes aufgezeichnet werden können.

Schlüsselwörter: Ambulante Überwachung, fetale Überwachung, Überwachung von physischen Aktivitäten.

\section{Résumé}

A propos d'un dispositif de mémoire portable pour les activités physiques et les informations des perceptions maternelles

Il faut connaître les conditions de vie des patients pour que les médecins veillent à une prise en charge adéquate de la maladie, et tout particulièrement de la grossesse à haut risque. Dans cette optique, nous avons réalisé un dispositif informatisé portable à mémoire des conditions pathologiques, pour enrigstrer les activités physiques, avec la perception maternelle des mouvements fotaux et de l'activité utérine pour la vie quotidienne, à la maison et au travail. Le dispositif emporté par la patiente est un système informatique de petite taille, à piles, CMOS 8 BIT (Taille $=107 \times 80 \times 30 \mathrm{~mm}, 240 \mathrm{~g}$ ); il est équipé d'interrupteurs à pression sur sa face supérieure et d'un interrupteur à mercure à l'intérieur. La patiente enregistre le moment de sa perception des mouvements fœtaux et des contractions utérines en appuyant sur les interrupteurs correspondants. De son côté l'interrupteur à mercure sert de capteur d'accélération et les activités physiques sont mesurées par le contage des actions "onoff" de l'interrupteur à mercure provoquées par ses mouvements. Par conséquent, le dispositif enregistre les activités physiques automatiquement grâce au portage de cette unité toute la journée. Le tamps d'enregistrement continu est supérieur à deux semaines. L'évaluation de la sensibilité de la mesure de l'activité physique a indiqué que le capteur par interrupteur à mercure est bien corrélé au taux de consommation d'oxygène au repos, et lors d'exercises modérés. Les données concernant l'utilisation de ce dispositif par 5 femmes enceintes ont montré que la différence quantitative des activités physiques entre le repos au lit et la vie domestique normale ainsi que les modifications journalières peuvent être nettement observées. A partir de ces résultats, les activités physiques et le mode de vie des patientes au cours de la vie quotidienne peuvent être suivis par ce dispositif.

Mots-clés: Surveillance fœtale, surveillance ambulatoire, surveillance de l'activité physique.

\section{References}

[1] BeHRman RE: Preventing low birth weight: A pediatric perspective. J of Pediatrics 107 (1985) 842
[2] LOTGERING FK, RD GILBERT, LD LONGO: Maternal and fetal responses to exercise during pregnancy. Physiological Reviews 65 (1985) 1

Toshitsune Hasegawa

College of Biomedical Technology

Osaka University

Machikaneyama-chou 1-1, Toyonaka

Osaka 560, Japan 